Article

\title{
Synthesis Polymer Styrene Butadiene Hybrid Latex with Laponite Organoclay as Filler via Emulsion Polymerization Technique for Application in Paper Coating
}

\author{
Bambang Soegijono ${ }^{1, *}$, Johannes Chanra ${ }^{2}$, Zhongwu Zheng' ${ }^{2}$ Puke $\mathrm{Mi}^{3}$ \\ 1 Department of Physics, Universitas Indonesia (UI), Depok, Indonesia \\ 2 Guangdong Tianyin Industrial Co.Ltd, Email : zzw@tycic.com (ZZW), m13817001001@163.com (JC) \\ 3 East China University of Science and Technology (ECUST), School of Material Science and Engineering, \\ Shanghai, China. $\quad$ Email : pkmi@ecust.edu.cn (M.Pk) \\ * Correspondence: naufal@ui.ac.id (BS) Tel.: +62-8161-324-952
}

\begin{abstract}
Synthesis of styrene butadiene hybrid latex was performed via emulsion polymerization technique using various amount of laponite clay as filler. Laponite clay was modified with cationic surfactant methyl triphenylphosphonium bromide (MTPB) with ion exchange technique prior to polymerization process. The main objective of the modification is to render the surface of the clay layers to more organophilic. Emulsion polymerization was performed under semi batch process using $2 \mathrm{~L}$ laboratory stainless steel reactor with temperature $85^{\circ} \mathrm{C}$ to $90^{\circ} \mathrm{C}$ for 8 hours. Polymer hybrid styrene butadiene latex was characterized for its physical and chemical properties with standard ASTM Methods. Characterization of its binding and printing properties were carried out with standard testing method (TAPPI Methods) using single coating formulation on $80 \mathrm{gsm}$ woodfree paper. Polymer hybrid latex based on styrene and butadiene monomers with laponite clay enhanced binding and printing properties of coated paper, addition of laponite clay to $6.0 \mathrm{wt} \%$ increased the binding resistance of the coated paper two times higher than pure latex. Reducing binder level become possible for cost saving.
\end{abstract}

Keywords: polymer hybrid latex; styrene butadiene; emulsion polymerization; printing properties; paper coating

\section{Introduction}

Styrene butadiene latex is an emulsion polymer containing monomer styrene, butadiene, acrylic acid, initiator, emulsifier and water. Latex normally synthesized via emulsion polymerization technique with temperature around $85^{\circ} \mathrm{C}$ to $95^{\circ} \mathrm{C}$ with pressure around 1 bar. Styrene butadiene latex extensively used in manufacturing coated paper. Moreover, Styrene butadiene latex is also widely used in the carpet industry for carpet backing especially in tufted. The global Styrene butadiene latex market is highly concentrated in nature with two top companies, Dow Chemicals and BASF. After the end of World War II, polymer chemists turned their minds to use Styrene butadiene latex in paints and coatings, the first effective water-based paints and coatings produced in order to challenge the market domination of oil-based and solvent-based products. The new products had little odor, non-flammable, were non-toxic and achieve similar quality to solvent based paints. Today, the application of styrene butadiene latex has proliferated too many more segments such as liquid applied membranes, construction adhesive and paperboard coatings for food packaging [1]. 
In paper and paperboard coatings, styrene butadiene latex has many uses, such as binder in paper coatings. Styrene butadiene latex enhances a pigment's binding power, it creates paper smoother, stiffer and more resistance to water and also much less expensive than other type of binders. Due to its pigment binding capacity and strength, making it the polymer of choice for paper coating and carpet backing [2]. The benefits of copolymerized styrene butadiene latex are many, including addition of organoclay as filler to form styrene butadiene hybrid polymer or nanocomposite. This modification offered this synthetic latex essential to an ever-widening group of markets and also to improve final performance of the products [3]. Depending on the interphase force between the polymer and organoclay, effect on different morphology are thermodynamically understood such as intercalated structure, flocculated structure and exfoliated structure $[4,5]$.

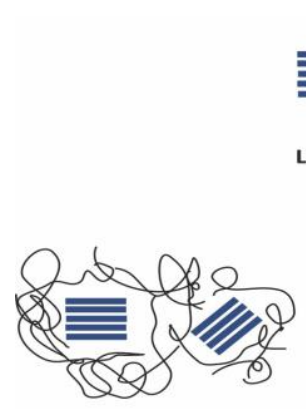

(a)

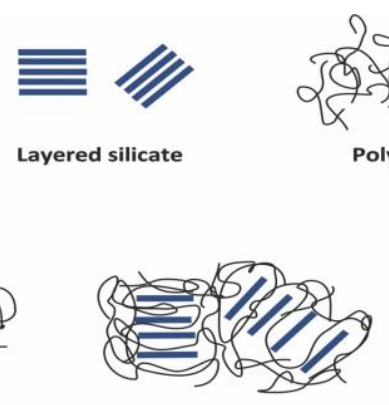

(b)

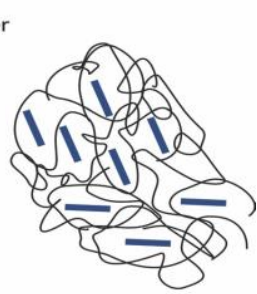

(c)

Figure 1. Various type structure of nanocomposite (a) intercalated (b) flocculated and (c) exfoliated [6]

To produce good nanocomposites, clays should be treated before being used into the polymer. Since the nature behavior of clay has hydrophilic characteristic, it is difficult to dispersed clays in polymer matrix. To change the clay behavior in order compatible to polymer matrix, clay should be modified before being dispersed into polymer matrix. For this reason, modification of clay should be done in order to break the forces on clay structure $[7,8]$. The objective of the process is done by cationic exchange technique in order to render the surface of the clay layers become more organophilic. The process improves dispersion of clay layers inside the polymer with specific experimental conditions [9]. Based on the structure of the clay, many surface modification technique available; the most common technique is cationic exchange reactions with surfactants. Alkylammonium type, phosphonium type and imidazolium type surfactants are the most commonly used, however selection of surfactant depends on further process in synthesis nanocomposite. Melt intercalation usually required organoclay with high thermal decomposition due to polymers involved has high melting points. Most of cationic surfactant in clay modification decreased surface energy of inorganic host and also increase interlayer distance of the clay; the process render to change the clay hydrophilicity $[10,11]$. The above process is intercalating process but it may render to exfoliation or delamination structure or flocculated structure due to excessive force and heat applied during modification process.

Emulsion polymerization of latex is a process of emulsification hydrophobic monomers by emulsifier agent or surfactant. Emulsion polymerization of latex initiate with water soluble initiator (e.g. potassium persulfate, KPS) or with oil soluble initiator $\left(2,2^{\prime}\right.$-azobisisobutyronitrile, AIBN) $[12,13]$. Typical polymerization monomers formed vinyl monomers structure $\left(\mathrm{CH}_{2}=\mathrm{CH}-\right)$, as emulsion polymerization is a process involving nucleation step, propagation step and termination step. Stabilization of polymer particles controlled by free radical polymerization mechanism in combination with colloidal phenomena $[14,15]$. Several emulsion polymerization technique were observed such as conventional emulsion polymerization. This emulsion polymerization involved hydrophobic monomers which are emulsified in water and commonly using water soluble initiator such as potassium persulfate [16]. Inverse emulsion polymerization with involved organic solvent with low polarity as polymerization media $[14,16]$. These two types of emulsion polymerization classified as oil-in-water $(\mathrm{o} / \mathrm{w})$ and water-in-oil (w/o) emulsifications [14]. Mini emulsion 
polymerization systems involved small monomer droplets in water and usually with $50 \mathrm{~nm}-1000$ nm sizes. To avoid Ostwald ripening during polymerization process, co-stabilizer hexadecane was used [17]. Micro polymerization technique process involved even with smaller monomer droplets (about $10 \mathrm{~nm}-100 \mathrm{~nm}$ ) and usually characterized by surfactant concentration with higher critical micelle concentration. Particle size of polymer around $10-50 \mathrm{~nm}$ and potassium persulfate initiators were commonly used as initiator [18,19]. The main ingredients of micro polymerization are monomers and water was used as dispersing medium together with water soluble initiator $[14,20,21]$. When the surfactant level exceeded its critical micelle concentration (CMC), surface tension decrease and forms spherical micelles as result monomers will enter to the vicinity of spherical micelles and reaction continue until all monomer in form of droplets are exhausted and micelles containing monomer increase in size. Each micelle has dimension in size around 2-10 nm and each micelle containing around $100-150$ surfactant molecules [14]. Usually, radical propagation start when water soluble initiator enter into the micelle, monomer droplets could not compete with micelle in capturing free radicals in aqueous phase due to relative small surface area [12]. As polymerization continues inside the micelle, addition of monomer from outside will increase the micelle size to form latex. Mechanism of emulsion polymerization shown on Figure 2.

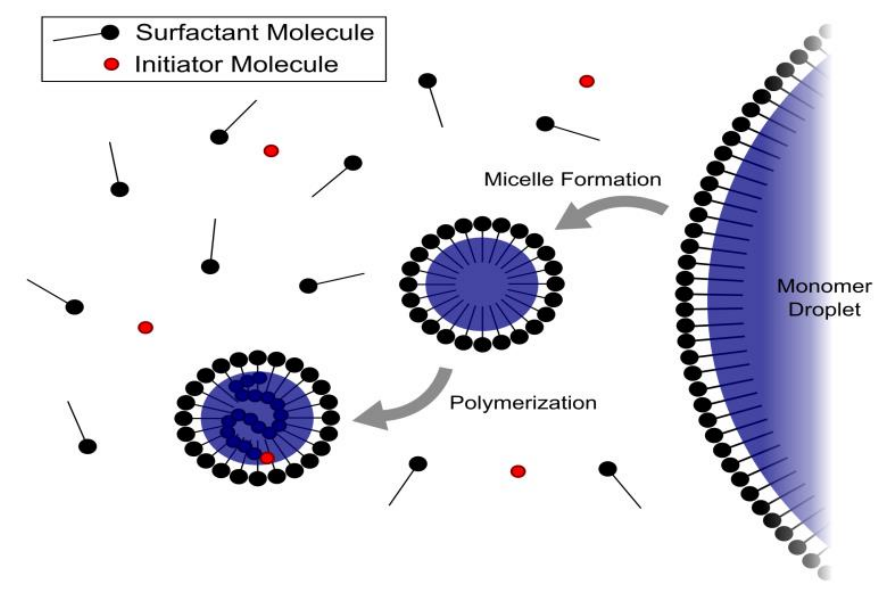

Figure 2. Mechanism of emulsion polymerization [22].

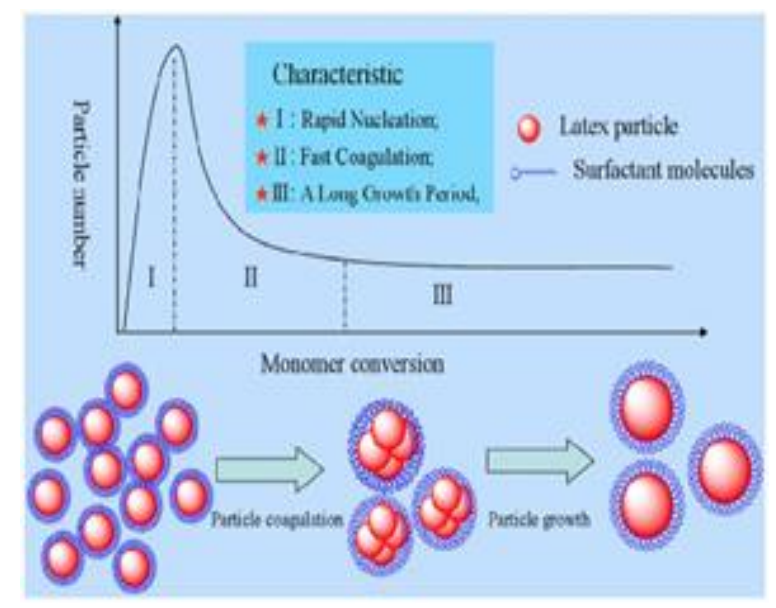

Figure 3. Emulsion polymerization interval [23].

Emulsion polymerization was performed in three main intervals as shown on Figure 3; the first interval is a separate monomer phase. During interval I, amount of particles increase versus time, this interval called particle nucleation interval. The interval was running until most of surfactant being used (micelle exhausted). The micelles form particle latex and nucleation process is controlled by amount of surfactant used and the process has a great influence in particle size distribution of 
latex [12]. The lower the surfactant concentration in emulsion system, nucleation period will be lower and as the result narrower particle size distribution will be obtained. During interval II (known as particle growth stage), polymerization process continued and particle size increase until all monomer droplets used. During this period, monomer droplet acts as droplets bank to supply growing particles. The polymer size increase as latex particles become monomer starved during Interval III and concentration of monomers decrease until end of polymerization process [12]. When all micelles are depleted, no more particles will be formed, the micelles disappear either by nucleated by free radical or by losing the surfactant as required for stabilization of existing growing particles. According to Harkins theory, micellar nucleation was a dominant nucleation mechanism. There are arguments that there are other possible sites where nucleation can occur; homogeneous nucleation for example, can take place when surfactant concentration lowers than CMC in surfactant free polymerization. It is believed that particle nucleation, homogenous nucleation and micelle nucleation co-exist in the emulsion polymerization. However, for many reasons, Harkin's theory still applies for the most case of the emulsion polymerization mechanism and other nucleation mechanism is often treated as secondary nucleation.

To synthesis stable water-based styrene butadiene hybrid latex, the stability of emulsion containing nanoclay can be affected by many factors such as clay particle size and its distribution. Particle latex should be large enough to covered up or encapsulate the clay; to achieve this, the particle size of the clay, the correct surface chemistry of clay and polymerization conditions play important roles to obtain stable latex [24]. The higher degree of clay intercalation or exfoliation, the greater improvement can be achieved in synthesis polymer hybrid latex. Therefore, it is important to understood, how the reaction conditions affect the efficiency of intercalation and exfoliation of the clay. The impact of organoclay on the properties of polymer styrene butadiene hybrid latex need to examine, the inclusion of organoclay and its loading level need to study. Zhaohui, Tong, 2007 [24] screening a variety synthesis approach in order to produce stable water-based latex of polymer clay nanocomposite using MMT-KSF as clay. However, they could not produce stable latex using emulsion and seeded emulsion polymerization, MMT-KSF separated from polymer particle after polymerization. The large particle size of MMT $(450 \mathrm{~nm})$ could not covered up by the latex particles or encapsulation process unsuccessful because of the large plate size of MMT. Norma.N. Herrera, et al , 2006 [25] synthesized water based latex polymer clay nanocomposite by first modified the laponite clay using silant agents $\gamma$-MPDES or $\gamma$ MPTMS before polymerization and then proceed with seeded emulsion polymerization, but no report on latex stability produced.

The primary goal of this research is to synthesize stable styrene butadiene water based latex with laponite organoclay. The surface chemistry of clay, modification technique will be discussed in order to achieve the goal. Synthesized latexes will be evaluated for its stability and properties before used in coating formulations. Coating formulations were prepared based on common single coat coating formulation, and coating process done by laboratory KCC Coater with $80 \mathrm{~g} / \mathrm{m}^{2}$ woodfree paper. Optical and printing properties of coated paper evaluated based on TAPPI Testing Methods.

\section{Materials and Methods}

\subsection{Material}

Laponite nanoclay (CEC) 100 meq/100g, supplied from Top Billion New Materials (Guangzhou) Co. Ltd. Methyl Triphenyl Phosphonium Bromide (MTPB) with purity 99,90\%, CAS No: 1779-49-3 supplied by Simagchem, China, Silver nitrate $\left(\mathrm{AgNO}_{3}\right.$ p.a) supplied by Sigma-Aldrich, Styrene monomer supplied by Styrene Mono Indonesia (SMI), Merak, Indonesia, Butadiene monomer, supplied by Sigma-Aldrich, Itaconic Acid, supplied by Taian Health Chemicals Co.Ltd, Shandong, China, Tert-Dodecyl Merchaptan (TDM) supplied by Shijiajuang, Sy Tech Co.Ltd, Hebei, China, Potassium Persulfate (KPS), supplied by Sigma Aldrich, Co. Ltd, China. SPS English China Clay, from Imerys, Calcium Carbonate (Omylate-90) from Omya, Dispersant from Tianyin Industrial Co. Ltd, carboxyl methyl cellulose (CMC Finfix 5) from C.P. Kelco China, sodium hydroxide (NaOH), 
from E-Merck, woodfree based paper, grammage 80 gsm from PT. Pindo Deli (Sinarmas), Indonesia, Starch Nylgum A85 from Avebe.

\subsection{Organoclay Preparation}

Laponite clay has lamellar structure with repeating layers of two silica tetrahedral layers and octahedral metal-oxide layer. There many methods are proposed for the surface modification of the nanoclay. One approach is to graft the clay surface by surface active monomer, which is render polymerization process on the nanoclay surface. However, this grafting method has weaknesses, it is easier to lose their activity during the modification process and nanoclay were not intercalated or exfoliated. The second approach is by using ion exchange technique, the exchangeable hydrated cations located in the interlayer facilitate the cation surfactant or organic monomer or polymer to insert into the layer in order to run pilarization and form expecting intercalated or exfoliated structure.

Unmodified laponite clay (20 g) with CEC $100 \mathrm{meq} / 100 \mathrm{~g}$ was dispersed in $1500 \mathrm{~mL}$ distilled water. Mixing process was done with high speed mechanical stirrer for 2 hours. Weight precisely MTPB surfactant with Sartorius balance model BA-B based on ratio $(\eta=2.0)$ of laponite CEC and dissolved in $500 \mathrm{ml}$ distilled water. Amount of cationic surfactant were calculated based on following equation:

$$
\text { Amount of surfactant }(\mathrm{g})=\eta \times \mathrm{CEC} \times \mathrm{A} \times \mathrm{B}
$$

Where $\eta$, ratio of CEC used based on previous research references from Hongping, He et al 2006 and Yunfei, $X_{i}[26,27]$. A, is the weight of laponite $(\mathrm{g})$ and B is the molecular weight of surfactant MTPB (MW = 357.22). Based on equation (1), amount of MTPB can be calculated and tabulated as following:

Tabel 1. Amount of MTPB surfactant for modification process.

\begin{tabular}{cccccc}
\hline $\begin{array}{c}\text { Surfactant } \\
\text { Type }\end{array}$ & $\begin{array}{c}\text { Molecular Weight, } \\
\mathrm{B},(\mathrm{g} / \mathrm{mol})\end{array}$ & $\begin{array}{c}\text { Ratio } \\
\text { Used }(\mathrm{\eta})\end{array}$ & $\begin{array}{c}\text { CEC } \\
(\mathrm{meq} / 100 \mathrm{~g})\end{array}$ & $\begin{array}{c}\text { Weight of clay, } \\
\mathrm{A},(\mathrm{g})\end{array}$ & $\begin{array}{c}\text { Amount of } \\
\text { surfactant }(\mathrm{g})\end{array}$ \\
\hline MTPB & 357.22 & 2.0 & 100 & 20.00 & 14.28 \\
\hline
\end{tabular}

The two solutions were mixed and stirred under high speed mechanical stirrer for 6 hours with controlled temperature $80^{\circ} \mathrm{C}$. To separate solution and precipitated, high speed centrifugal was used with $4000 \mathrm{rpm}$, several washing were done until obtained solution free of bromine (test with AgNO3 $0.1 \mathrm{M})$. Keep the precipitated under vacuum oven at $80^{\circ} \mathrm{C}$ for 1 night. Finally, ground the powder with pestle mortal and keep the powder on desiccator for storage. The samples were ready to be used for characterization. Characterization were performed by x-ray diffraction (XRD), fourier transform infra-red (FTIR) and transmission electronic microscope (TEM) thermals decomposition will be done by thermogravimetric analysis (TGA).

\subsection{Synthesis of latex with emulsion polymerization.}

The seeded emulsion polymerization was conducted with Laponite-MTPB with oil soluble initiator AIBN. Firstly, the Laponite-MTPB was copolymerized with monomer styrene through polymerization vessel. The Laponite-MTPB with $15-20 \%$ surface coverage of polystyrene was acted as seed for emulsion polymerization.

For emulsion polymerization process, polymerization reactor was purging with Nitrogen at room temperature for 30 minutes and slowly increases the reactor vessel temperature to $80+/-2^{\circ} \mathrm{C}$. Feeding monomer mix and aqueous mix was performed until the polymerization temperature reached. The monomers feed was arranged for 3 hours feeding time and the second batch of water for 5 hours feeding time. Maintain the temperature of the reactor for $80^{\circ} \mathrm{C}+/-2^{\circ} \mathrm{C}$. After all addition finished, hold the temperature for 60 minutes at $80^{\circ} \mathrm{C}$. Cooling the polymerization vessel to $30^{\circ} \mathrm{C}$ and 
filter the latex using stainless steel screen 100 mesh to remove all solid impurities. Latex can be used for characterization and applications on coating formulations.

Table 2. Styrene Butadiene Hybrid Latex Recipe.

\begin{tabular}{|c|c|c|}
\hline $\begin{array}{l}\text { Recipe Part } \\
\text { (BOM) }\end{array}$ & Initial Reactor Charge & $\begin{array}{l}\text { Weight, } \\
\text { in gram }\end{array}$ \\
\hline \multicolumn{3}{|c|}{ Pre-dispersed Seed Latex (Laponite-MTPB) } \\
\hline 116.8 & Distilled Water & 688.3 \\
\hline 40.0 & Butadine Monomer $\gamma_{3}$. & 235.9 \\
\hline 56.0 & Styrene Monomer $\}$ sours reeaing & 330.3 \\
\hline 4.0 & Acrylid Acid & 18.0 \\
\hline 0.2 & TDM & 4.7 \\
\hline 1.2 & Potassium Persulfate, KPS & 7.1 \\
\hline 15.0 & Distilled Water & 88.4 \\
\hline 0.75 & Anionic Surfactant (SDS) & 9.8 \\
\hline 0.2 & Sodium Hydroxide, $\mathrm{NaOH}$ & 5.9 \\
\hline 20.0 & Distilled Water $\} \quad$ (5 hours feeding) & 117.5 \\
\hline
\end{tabular}

\subsection{Coating Color Preparation.}

Mixed of pigments (clay and calcium carbonate), dispersing agent (Dispex N40), binder (latex) and distilled water with $\mathrm{NaOH}$ formed coating colors.

Table 3. Coating colour formulation for single coating.

\begin{tabular}{cc} 
Ingedients & $\begin{array}{c}\text { Parts, based on } \\
\text { pigments }\end{array}$ \\
\hline Distilled Water & as required \\
Dispesing agent (sodium polyacrylate) & 0.2 \\
Kaolin, SPS English China Clays, $\rho=2.59 \mathrm{~g} / \mathrm{cm}^{3}$ & 70.0 \\
Calcium Carbonate, Omya-90 & 30.0 \\
Binder, Latex, 50\% solid content & 12.0 \\
Starch, Nylgum A85 from Avebe & 2.0 \\
Carboxy methil cellulose (cmc) Finfix 5 & 0.5 \\
Sodium Hydroxide solution, NaOH 25\% & 0.2 \\
Solid Content, $\%$ & $65.0-68.0$ \\
Broekfield Viscosity, cPs & $1200-1800$ \\
Final pH & 9.0 \\
Base paper, woodfree & $80 \mathrm{gsm}$ \\
Coating weight applied & $18-20 \mathrm{gsm}$ \\
\hline
\end{tabular}

\subsection{Coating process.}

Coating process was done with simple K Hand Coater from RK Printcoat Instruments. K101 coater equipped with $\mathrm{K}$ Bar Coating and after coated the coating was heated under constant temperature oven $135^{\circ} \mathrm{C}$ for 5 minutes and calendered with three roll laboratory calender machine 
PE 204 from Premier Enterprise, India for 2 nips, heated to $130^{\circ} \mathrm{C}$ with pressure 10 bars. The coating weight was controlled with $20+/-2$ gsm on 80 gsm woodfree paper and measured after dried (before calendaring).

Materials and Methods should be described with sufficient details to allow others to replicate and build on published results. Please note that publication of your manuscript implicates that you must make all materials, data, computer code, and protocols associated with the publication available to readers. Please disclose at the submission stage any restrictions on the availability of materials or information. New methods and protocols should be described in detail while well-established methods can be briefly described and appropriately cited.

Research manuscripts reporting large datasets that are deposited in a publicly available database should specify where the data have been deposited and provide the relevant accession numbers. If the accession numbers have not yet been obtained at the time of submission, please state that they will be provided during review. They must be provided prior to publication.

Interventionary studies involving animals or humans, and other studies require ethical approval must list the authority that provided approval and the corresponding ethical approval code.

\section{Results and Discussions}

\subsection{Modification and dispersion of laponite organoclay.}

The pristine-laponite is hydrophilic and requires pre-modification in order to be dispersed in styrene and butadiene monomers. Pristine-laponite clay was converted to organoclay using MTPB surfactant. The morphological, structural and thermal characteristics were discussed in this chapter.

XRD analysis was carried out in order to determine the basal spacing or interlayer distance of laponite organoclay (d001). Using XRD, intercalated or exfoliated nanocomposite can be determined, in this analysis XRD measurement conducted in small angle $3^{\circ}$ to $30^{\circ}$ with diffractometer system XPERT-PRO, measurement with Cuk $\alpha 1$ with $\lambda=1.54060$ Å running with generator setting $30 \mathrm{~mA}, 40$ $\mathrm{kV}$. Laponite clay exhibited a basal spacing or interlayer distance (d001) at $6.669^{\circ}$, which according to Bragg's law ( $\mathrm{n} \lambda=2 \mathrm{~d} \sin \Theta$ ) has basal spacing of $1.32 \mathrm{~nm}$, after modification with MTPB, the interlayer spacing decreased to lower angle $6.029^{\circ}$ and basal spacing increased to $1.46 \mathrm{~nm}$ due to pilarization or structure changed[28].

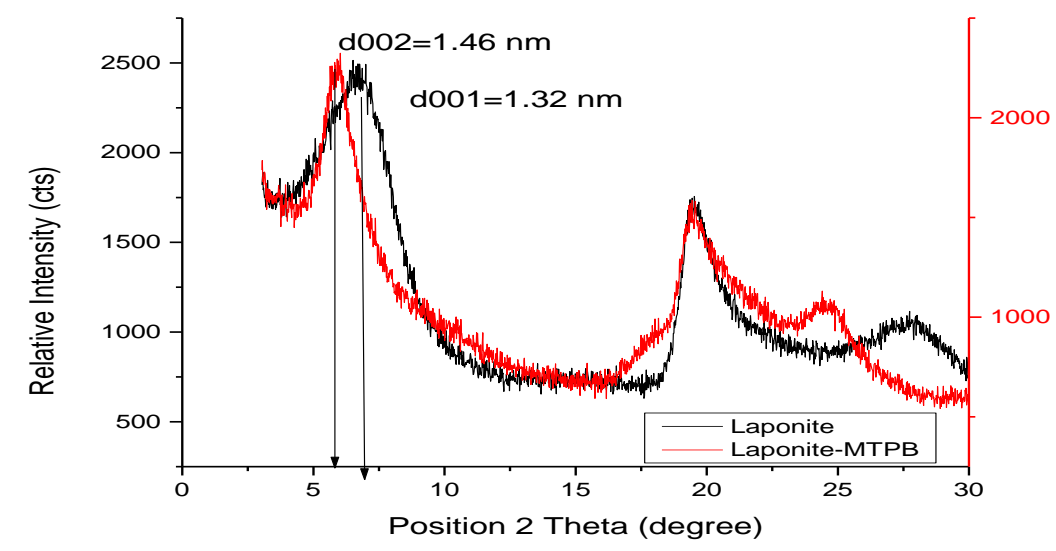

Figure 4. XRD diffractogram of pristine-laponite and modified laponite (Laponite-MTPB).

It is proved the presence of alkylphosphonium group in the silicate layered interlayer space were increased the basal spacing of laponite clay due to intercalation of the surfactant ions.

Infrared spectra of laponite and modified laponite clay with methyl triphenyl phosphonium bromide shown on Figure 5. New peaks appeared on modified laponite clay on $1414 \mathrm{~cm}^{-1}, 1467 \mathrm{~cm}^{-1}$, $2874 \mathrm{~cm}^{-1}, 2934 \mathrm{~cm}-1$, and $2962 \mathrm{~cm}^{-1}$. Based on chemicals composition analysis by suppler, 
laponite nanoclay consisted of $\mathrm{SiO}_{2} 59.5 \%, \mathrm{MgO} 27.5 \%, \mathrm{Li}_{2} \mathrm{O} 0.8 \%, \mathrm{Na}_{2} \mathrm{O} 2.8 \%$ and $\mathrm{LOI} 8.2 \%$ with chemical structure $\mathrm{Li}_{0.8}: \mathrm{Li}_{0.8}\left[\mathrm{Mg}_{2 \cdot 2} \mathrm{Li}_{0.8}\right] \mathrm{Si}_{4} \mathrm{O}_{10} \mathrm{~F}_{2}$ [29]. Frequencies $\left(\mathrm{cm}^{-1}\right)$ of $\mathrm{OH}$ stretching shown on $3686 \mathrm{~cm}^{-1}, \mathrm{Mg}-\mathrm{O}$ vibration of laponite clay at $426 \mathrm{~cm}^{-1}$, Si-O vibration showns on 648 and $981 \mathrm{~cm}^{-1}$. New peaks on $1414 \mathrm{~cm}^{-1}, 1467 \mathrm{~cm}^{-1}$, and $2874 \mathrm{~cm}^{-1}$ indicated attaching of alkyl phosphonium groups on laponite surface or inserted of alkyl groups into laponite interlayer. Interestingly, the vibrational spectra of $(-\mathrm{OH})$ containing in laponite sample measured at ambient conditions are not shown on IR spectra but appeared on modified laponite's spectra.

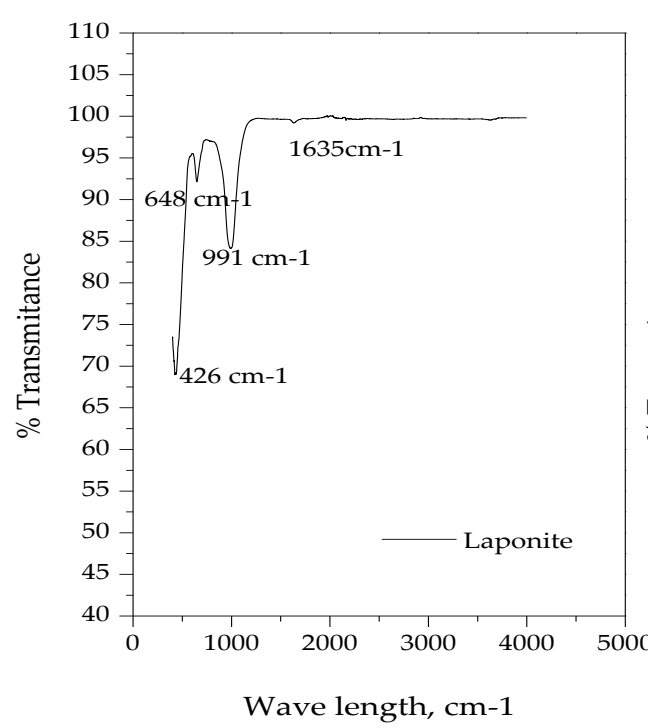

(a)

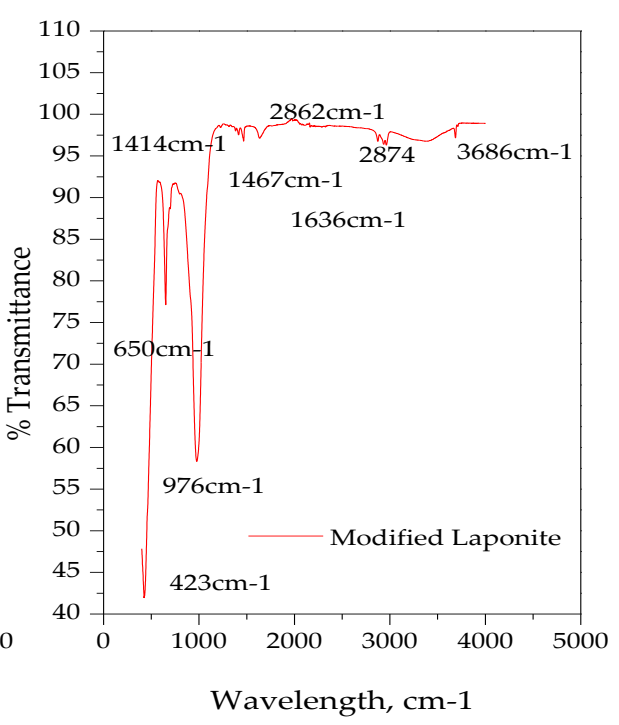

(b)

Figure 5. FTIR Spectra of (a) Laponite Nanoclay and (b) modified Laponite.

The peaks intensity of modified laponite was rise due to water absorption during surface modification process, in addition to the stretching vibrations was discussed, the $\mathrm{H}-\mathrm{O}-\mathrm{H}$ angle deformation frequency can be observed at $1636 \mathrm{~cm}^{-1}$, the interlayer water was found to give arise to diffuse in unspecific spectra of 976 to $650 \mathrm{~cm}^{-1}$ region [30]. The alkyl phosphonium cation exchange enables the conversion of the hydrophic interior laponite nanoclay surface into the hydrophobic surface, which increase the basal spacing of Laponite nanoclay. FTIR confirmed the XRD results which are examine the presence of MTPB groups in the nanoclay.

\subsection{Synthesis polymer styrene butadiene hybrid latex}

Particle size and surface modification of nanoclay play a critical role on stability of emulsion, if the particle size is too large; it is difficult to form a stable emulsion in the oil phase. Small particle size of laponite nanoclay was selected and according to previous research by Zhaohui,Tong (2007), using laponite or saponite nanoclay could form a stable dispersion [24]. Surface properties of nanoclay also play important role in the dispersibility of intercalated clay in monomer. Laponite untreated nanoclay are organophobic and difficult to dispers in organo-media. Modification of laponite nanoclay with MTPB, has changed the properties of laponite to organophilic and become more compatible to monomers.

Mechanical homogenization with high speed stirrer is an important step to prepare stable emulsion; monomer droplets play as monomer reservoir to supply monomer to the growing polymer particles. The final conversion after 8 hours polymerization without and with organoclay addition is $99.8 \%, 99.2 \%, 98.2 \% 97.5 \%, 96.2 \%, 95.0 \%$. Addition of organoclay was done with $2.0 \%$, $4.0 \%, 6.0 \%, 8.0 \%$ and $10.0 \%$ based on monomer weight. It was conclude from Table 4 that polymerization rate or conversion degree decreased with addition of organoclay in the emulsion. It can be explained that the reactivity of radicals and living polymers is lower due to presence of 
organoclay particles and adsorption of the living polymers affected by large organoclay surface. Particle size distribution and polydispersibility of latex increased with addition of organoclay as shown on Table 4 results. Addition of organoclay decreased polymerization rate or reduced monomer conversion rate also shown on Zhaohui, Tong (2007) research [24], similar results obtained by this studies. Addition of laponite organoclay up to $6.0 \mathrm{wt} \%$ decreased polymerization rate to $97.2 \%$, further addition affected latex stability with creased high amount of coagulum content $(>4.0$ $\mathrm{wt} \%$ ) and blocked the filtered screen during filteration steps. High amount of unconverted monomer were created on addition of 8.0 to $10.0 \mathrm{wt} \%$ laponite organoclay due to low polymerization rate.

Table 4. Effect of addition laponite organoclay on polymerization results.

\begin{tabular}{cccccc}
\hline Sample & $\begin{array}{c}\text { Organoclay } \\
\text { Addition } \\
(\mathrm{wt} \%)\end{array}$ & $\begin{array}{c}\text { Particle Size } \\
\text { Average } \\
(\mathrm{nm})\end{array}$ & $\begin{array}{c}\text { Poly } \\
\text { Index }\end{array}$ & $\begin{array}{c}\text { Polymerization } \\
\text { Rate (\%) }\end{array}$ & $\begin{array}{c}\text { Coagulum } \\
\text { Content } \\
(\%)\end{array}$ \\
\hline A & 0.0 & 112 & 0.198 & 99.8 & 0.158 \\
B & 2.0 & 126 & 0.165 & 99.2 & 0.356 \\
C & 4.0 & 132 & 0.154 & 98.1 & 0.568 \\
D & 6.0 & 150 & 0.148 & 97.2 & 0.787 \\
E & 8.0 & 358 & 0.138 & 95.2 & 4.250 \\
F & 10.0 & 488 & 0.122 & 90.8 & 8.899 \\
\hline
\end{tabular}

Latex characterization and stability test results are shown on Table 5.

Table 5. Latex characteristics and storage stability tests.

\begin{tabular}{ccccccc}
\hline & \multicolumn{7}{c}{ Sample Latex Label } \\
Test Parameter & A & B & C & D & E & F \\
\hline Latex clour & Milky & Milky & Milky & Milky & Milky & Milky \\
& white & white & white & white & white & white \\
Broekfield Viscosity, 50 rpm, cps & 258 & 342 & 380 & 412 & 680 & 1150 \\
Solid Content, \% & 50.40 & 50.10 & 50.30 & 50.25 & 49.80 & 49.50 \\
Coagulum Content, 200 mesh, \% & 0.158 & 0.356 & 0.568 & 0.787 & 4.250 & 8.899 \\
Glass Temperature (Tg), ${ }^{\circ} \mathrm{C}$ & 0.0 & 2.0 & 3.8 & 4.4 & 6.0 & 8.8 \\
Storage Stability Test (coagulum content, \%) & & & & & & \\
0 hrs & 0.158 & 0.356 & 0.568 & 0.787 & 4.250 & 8.899 \\
$24 \mathrm{hrs}$ & 0.056 & 0.067 & 0.071 & 0.089 & 3.211 & 5.221 \\
$48 \mathrm{hrs}$ & 0.042 & 0.047 & 0.056 & 0.063 & 2.110 & 3.220 \\
$72 \mathrm{hrs}$ & 0.022 & 0.033 & 0.038 & 0.048 & 1.220 & 1.889 \\
Total, \% & 0.278 & 0.503 & 0.733 & 0.987 & 10.791 & 19.229 \\
\hline
\end{tabular}

Addition of organoclay increased latex Broekfield Viscosity and Tg values, literature reported has reported regarding $\mathrm{Tg}$ of polymer reinforced by clay platelets [31,32]. Increased in $\mathrm{Tg}$ attributed to the restricted thermal motions of polymer chains effect of interaction of clay platelets surface and polymer chains $[33,34]$ and decreased of $\mathrm{Tg}$ can be associated with plasticization of the materials by the alkyl chains of the MTPB [35]. Normally theoretical Tg of unfilled polymer can be calculated (Table 6.) and the value were compared with experimental figures in order to examine polymerization form copolymer or homo polymer. Based on theoretical calculation, calculated Tg is around $-1.2^{\circ} \mathrm{C}$, and from experimental results with DSC only single $\mathrm{Tg}$ were obtained and close to 
$0.0^{\circ} \mathrm{C}$, it means that polymer latex formed in emulsion polymerization of styrene and butadiene is copolymer and most of styrene and butadiene have been converted to polymer. According to DSC measurements, the $\mathrm{Tg}$ of styrene butadiene latex with ratio 40:60 gradually increased with increasing laponite organoclay content from $0.0^{\circ} \mathrm{C}$ in the unfilled material to $8.8^{\circ} \mathrm{C}$ with $10.0 \mathrm{wt} \%$ of laponite organoclay. All samples with addition of laponite organoclay showed higher $\mathrm{Tg}$ relative to unfilled SB latex. Higher $\mathrm{Tg}$ is attributed to copolymer chain mobility by the presence of the rigid laponite organoclay platelets.

Table 6. Styrene Butadiene copolymer unfilled latex Tg calculation.

\begin{tabular}{|c|c|c|c|c|c|c|c|}
\hline Monomer & Ratio & $\begin{array}{c}\mathrm{Tg} \\
\left({ }^{\circ} \mathrm{C}\right)\end{array}$ & $\mathrm{T}=\mathrm{Tg}+273 \mathrm{~K}$ & $\mathrm{~W}=$ Ratio $/ 100$ & $\mathrm{~W} / \mathrm{T}$ & $\begin{array}{l}\mathrm{Tg} \text { in } \mathrm{K}= \\
1 /(\mathrm{W} / \mathrm{T})\end{array}$ & $\mathrm{Tg},{ }^{\circ} \mathrm{C}$ \\
\hline Styrene & 56.0 & 100 & 373 & 0.56 & 0.0015 & & \\
\hline Butadiene & 40.0 & -80 & 193 & 0.40 & 0.0021 & & \\
\hline Acrilic Acid & 4.0 & 106 & 379 & 0.04 & 0.0001 & & \\
\hline
\end{tabular}

\subsubsection{Chemical stability of latexes.}

Styrene butadiene latex produced with emulsion polymerization technique involved of anionic surfactants (SLS or SDS) with charged functional groups for stabilization and usually it is possible to keep the latex in stabile conditions for at least 6 months. However, the stability derived from electrostatic repulsion could be decrease or lost due to counter ions available in the emulsion, which neutralize electrostatic charges. When the electrostatic charges disappeared, coagulation or gelation occurs when the $\mathrm{pH}$ of latex decreased to acidic conditions. To study the stability of latex as function of $\mathrm{pH}$, the zeta potential of latexes were measured as shown in Figure 6. The stability of styrene butadiene latexes was studied by measuring the Broekfield viscosity at several pH levels (Figure 6). Zeta potential of styrene butadiene latex with addition of laponite organoclay was greater than styrene butadiene latex unfilled with organoclay, it is observed that the styrene butadiene latex with organoclay addition was stable in neutral and alkali conditions (6.0 to 9.0). However, in acidic conditions, styrene butadiene latex with organoclay formed agglomerates and dispersion completely gelled, indicated the latex lost its stability.

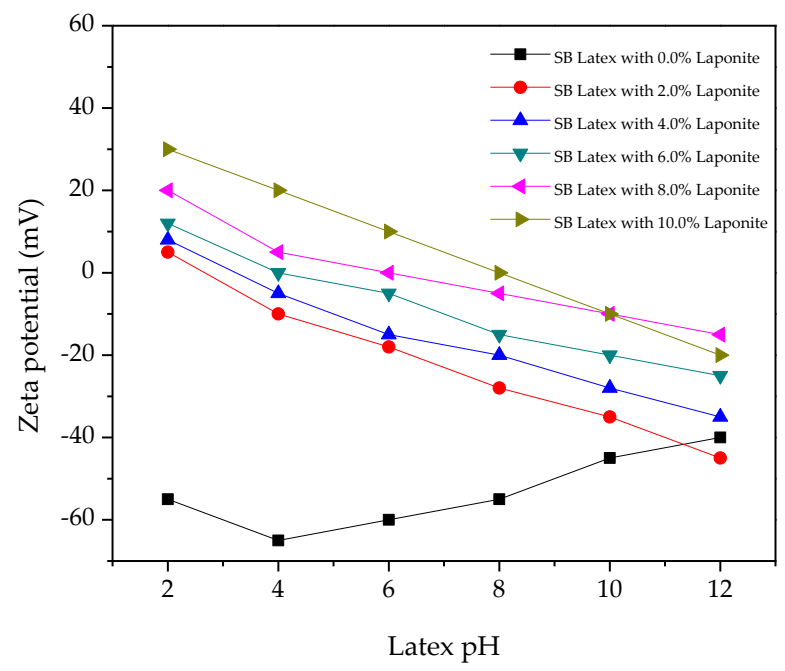

Figure 6. Zeta potential of styrene butadiene latex as function of $\mathrm{pH}$. 


\subsection{Coating color preparation and coating process}

Latex as binder in coating color is the second most important component in after the pigments. The function of binder in coating colors are to give cohesion force or to bind pigments to base paper, binding pigment particles to each other and filling of voids between pigment particles. Binder offered strength required for coated paper in order to pass printing and converting process. Styrene butadiene latex is a water based polymer with particle size 300-500nm with different composition of monomer styrene and butadiene. The component ratio in the copolymer styrene butadiene latex usually consisted of styrene $60 \%$ and butadiene $40 \%$. Surface composition is differentiated by adsorption of anionic surfactants, which are act as stabilizing agents [36].

\subsubsection{Sedimentation of coating color}

In order to evaluate whether the flocculation of the coating color is induced by latex with organoclay addition, a sedimentation experiment was carried out. In this experiment, centrifugation of the coating colour followed by sediment measurement after decanting the supernatant were made. The results were shown in Figure 7.

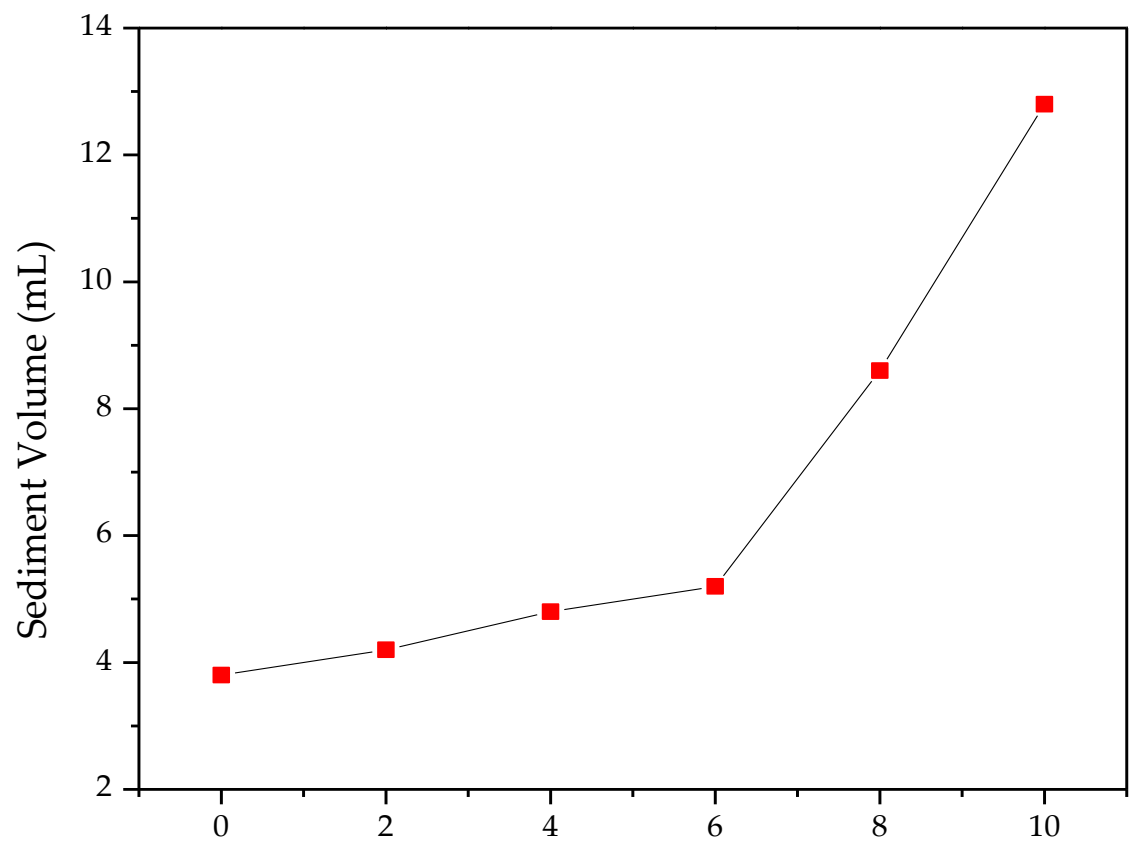

Laponite organoclay level (wt\%)

Figure 7. Sediment volume of coating color with addition of laponite organoclay in latex.

It can be seen that addition of laponite organoclay in latex gave higher sedimentation volume of coating colour, addition of laponite organoclay with $8.0 \mathrm{wt} \%$ and $10.0 \mathrm{wt} \%$ in latexes gave a higher sedimentation volume, indicating that the organoclay caused formation of weakly flocculated structure of the coating color.

\subsubsection{Viscosity and water retention of coating color}

Effect of addition organoclay in styrene butadiene latex also shown on its viscosity and water retention of coating colors. All coating colors showed shear thinning behavior [37]. Organoclay increased interaction between coating components and resulted higher viscosity of coating colour 
compared with coating color containing only with SB latex unfilled with organoclay. Table 7 shows the low shear viscosity and water retention of coating color with solid content of $65 \%$ at $\mathrm{pH} 9.0$. Addition of organoclay in latex increased the viscosity of the coating color.

A typical coat weight applied is between $15-20 \mathrm{~g} / \mathrm{m}^{2}$; to obtain a correct coat weight, selection rods coater is essential, while the metering speed are kept constant.

Tabel 7. Effect of organoclay in latex on viscosity and water retention of coating colours.

\begin{tabular}{ccccccc}
\hline & $\begin{array}{c}\text { SB Latex } \\
\text { without } \\
\text { Testing Parameter }\end{array}$ & $\begin{array}{c}\text { SB Latex } \\
\text { with } 2.0 \%\end{array}$ & $\begin{array}{c}\text { SB Latex } \\
\text { with } 4.0 \%\end{array}$ & $\begin{array}{c}\text { SB Latex } \\
\text { with } 6.0 \%\end{array}$ & $\begin{array}{c}\text { SB Latex } \\
\text { with } 8.0 \%\end{array}$ & $\begin{array}{c}\text { SB Latex } \\
\text { with } 10.0 \%\end{array}$ \\
& organoclay & organoclay & organoclay & organoclay & organoclay & organoclay \\
\hline Dewatering $\left(\mathrm{g} / \mathrm{m}^{2}\right)$ & 118.8 & 108.2 & 106.8 & 104.8 & 99.8 & 98.2 \\
Viscosity $(\mathrm{cps})$ & 1380 & 1480 & 1520 & 1580 & 1680 & 1800 \\
\hline
\end{tabular}

Dewatering of coating color is influenced by the hydrophilicity of the coating components, Addition of organoclay in latex reduced the dewatering effect of the coating colours or increased the water retention value of the coating colors. Interlayer laponite nanoclay still contains hydrophilic parts which absorbed water via hydrogen bonding and increased the water retention capacity of the coating color. It was found that higher organoclay content in latex, resulted higher water retention of the coating colors.

\subsubsection{Pore structure of coating color}

Coating color containing organoclay in the latex were coated on plastic films. The porosity of dried films was compared with the one without addition of organoclay. Table 8 shows the total intrusion volume and porosity of the coating layer. Addition of organoclay in latex increased the porosity of the coating layer compare to reference layer. More addition of organoclay in latex, the mercury intrusion to coating layer increased, it is indicating that a more porous coating composite was formed. The porosity of coating color was measured by mercury intrusion porosimetry (AutoPore IV 9500) form Micromeritics Instruments Corporation.

Table 8. Pore characteristics of coating layer.

\begin{tabular}{ccc}
\hline $\begin{array}{c}\text { SB Latex with } \\
\text { organoclay }\end{array}$ & $\begin{array}{c}\text { Total Intrusion } \\
\text { Volume }(\mathrm{mL} / \mathrm{g})\end{array}$ & $\begin{array}{c}\text { Porosity } \\
(\%)\end{array}$ \\
\hline 0.0 & 0.158 & 28.4 \\
2.0 & 0.188 & 32.9 \\
4.0 & 0.208 & 38.8 \\
6.0 & 0.226 & 42.2 \\
8.0 & 0.408 & 50.8 \\
10.0 & 0.886 & 80.8 \\
\hline
\end{tabular}

\subsubsection{Effect of base paper in coating layer formation}

Effect of base paper in coating has been studied with wood-containing base paper but less information on woodfree base papers. Comparing to wood-containing base papers, woodfree base papers is more porous structure and has hydrophilic behavior therefore giving more water absorbent. Usually in coating process, the contact time of coating color touching the base paper was very short (1-4 ms). Due to high pressure applied in calendering, coating layer formation in base paper can be based on pressure penetration [38,39]. Base paper properties measured are shown on Table 9. Base paper collected from PT.Pindo Deli, Sinarmas plant at Karawang, West Java with grammage 80 gsm. 
Table 9. Properties analysis of base paper.

\begin{tabular}{ccccccc}
\hline Base paper & $\begin{array}{c}\text { Structure Filler } \\
\text { Surface, } \%\end{array}$ & $\begin{array}{c}\text { Roughmess } \\
\text { Bendtsen, } \\
\mathrm{mL} / \mathrm{min}\end{array}$ & $\begin{array}{c}\text { Parker } \\
\text { Print Surf } \\
\text { (PPS), } \mu \mathrm{m}\end{array}$ & $\begin{array}{c}\text { Absorption Nozzle } \\
\text { Apllication }\end{array}$ & $\begin{array}{c}\text { Oil } \\
\text { Liquid } \\
\text { Phase }\end{array}$ & $\begin{array}{c}\text { Chemistry } \\
\text { FIBRO, contact } \\
\text { Angle, }^{\circ}\end{array}$ \\
\hline Top & 30 & 380 & 5.8 & 168 & 0.6 & 90.2 \\
Bottom & 10 & 680 & 8.8 & 176 & 3.8 & 91.5 \\
\hline
\end{tabular}

Coating color transfer to the coating roll which is increased as rod pressure was reduced; it is indicated by surface openness by oil absorption rate as important parameter in controlling coating layer formation. Other properties such as roughness or smoothness also influence on coating layer formation. The laboratory rod coater, namely, "K Control Coater (KCC)" (Figure 8) was use ad coating device. KCC consists of several types of rods to be used for deposition of coating color.
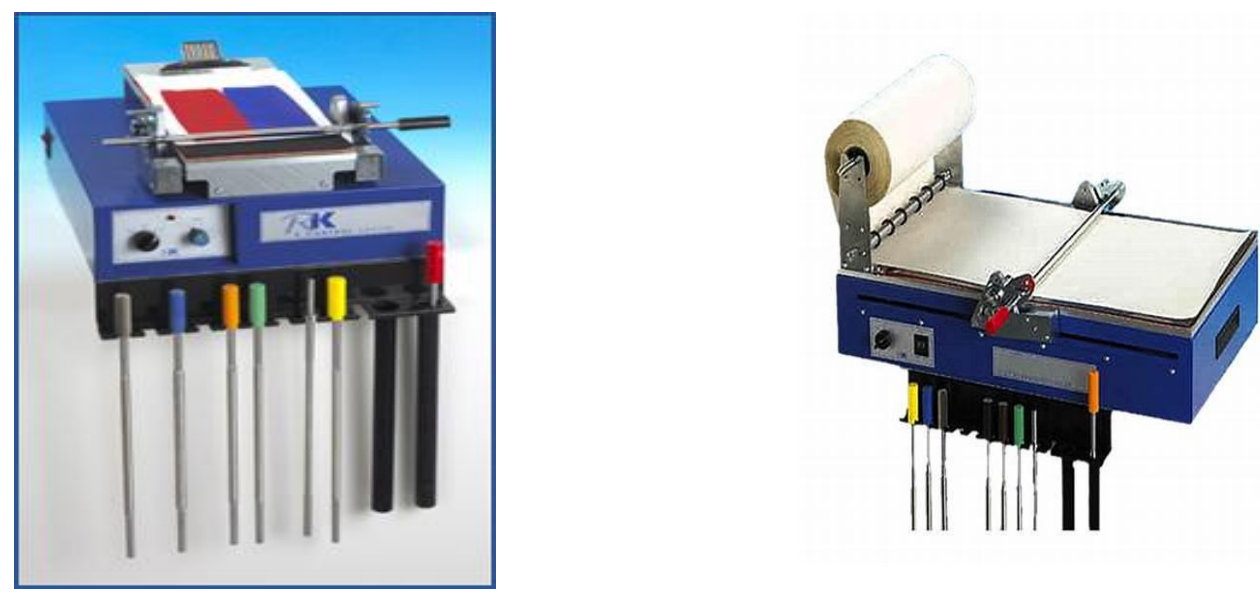

Figure 8. K Control Coater (KCC) with hand rods (K Control Coater User Manual).

\subsubsection{Optimization of coating process.}

Before the actual coating process, several variables involving in the coating color should be optimized. The first parameter is viscosity of coating color, accepted range should be between 1000 $\mathrm{mPa}$ to $1800 \mathrm{mPa}$ [40].

Coating colors usually have pseudoplastic shear rate behavior, a high viscosity may caused problem especially in sub-processes that experience in low shear rate area. Process involved in pumping the coating color and returning back to coating batch could cause increased in viscosity and might result into clogging. To regulate the viscosity of coating color, amount of carboxy methyl cellulose (CMC) could be adjusted, normally in the level of 0.2 to $0.5 \mathrm{wt} \%$. Among of other possibility to adjust the viscosity of coating color is increasing or decreasing of coating color solid content. A typical coat weight applied in dispersion coating is $15-20 \mathrm{~g} / \mathrm{m}^{2}$, the coat weight obtained by selection of the right rod bars while the metering speed was kept constant. Richmond et al (2014) reported a coat weight as function of metering speed using CLC Coater and Linnonma and Treft (2009) reported the coat weight as the function of rod bars [41,42]. The rod speed did not appear to have correlation on coating thickness, coating thickness typically range between $10-15 \mu \mathrm{m}$.

Binder migration was not studied in this research due to various parameter need to be considered, latex as binder can be migrate during the coating and drying process. A comprehensive 
studied on binder and starch migration in coating process have been done by Emilia Golebiowska (2015). Emilia Golebiowska shows that homogenous mixed coating with starch and latex tend to be separated into separate layers due to the size of starch and latex particles are different which allows for starch particles migrate towards into base paper while the latex particle remains on the top after drying process [43].

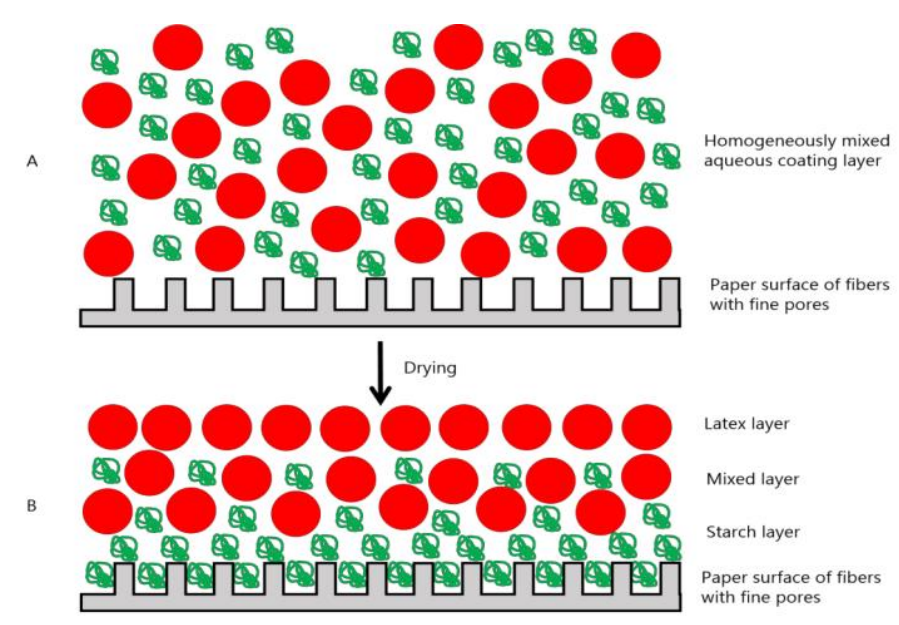

Figure 9. Binder migration of starch and latex into base paper [43].

The main mechanism for formation of coating layer during coating process was by pressure induced penetration of coating color liquid into the voids area between the fibers. Coating color penetrated into walls of fibers located in the surface layers. Water sorption into the fibers was slower than capillary penetration, the movement of coating color process assumed by diffusion during coating process and by capillary penetration after the nip. However, the mechanism of water transport into the fibers wall still unclear, further studies and simulation under dynamic conditions are needed to be done in order to prove the movement of water into the fiber wall during coating process.

\subsubsection{Coated paper properties}

\subsubsection{Optical properties}

Most of the optical properties come from the coating, the base paper influencing the coverage of the coating, roughness or smoothness and yellowing. The quality of the image obtained on coated paper is much higher than uncoated paper, the reason is coated paper have less porous and better smoothness. A smoother surface means a more accurate of the image transferred from printing plate to paper surface and less porous means the inks are held out more on the surface, affected to a brighter and more colorful image.

\begin{tabular}{|c|c|}
\hline \multicolumn{2}{|c|}{ Optical Properties } \\
\hline Pigments & \\
\hline Binder & Sheet gloss \\
\hline Co-binder & Brightness \\
\hline OBA/Dye & Opacity \\
\hline Coat weight & Coverage \\
\hline Coater & Smoothness \\
\hline Calendering & Yellowing Index \\
\hline Basepaper & \\
\hline
\end{tabular}

Figure 10. Factor influence on optical properties of coated paper 
Optical properties of coated paper based on type of latex used shown on Table 10.

Table 10. Optical properties measurement of coated paper with different latexes.

\begin{tabular}{|c|c|c|c|c|c|c|}
\hline Testing Parameter & $\begin{array}{c}\text { Latex A, } \\
\text { Blank }\end{array}$ & $\begin{array}{c}\text { Latex B, } \\
2.0 \% \\
\text { Laponite }\end{array}$ & $\begin{array}{c}\text { Latex C, } \\
4.0 \% \\
\text { Laponite }\end{array}$ & $\begin{array}{c}\text { Latex D, } \\
6.0 \% \\
\text { Laponite }\end{array}$ & $\begin{array}{c}\text { Latex E, } \\
8.0 \% \\
\text { Laponite }\end{array}$ & $\begin{array}{c}\text { Latex F, } \\
10.0 \% \\
\text { Laponite }\end{array}$ \\
\hline Sheet gloss, Tappi T480 om-92 & 68.2 & 70.8 & 71.2 & 72.1 & 72.2 & 72.5 \\
\hline $\begin{array}{l}\text { Brightness, Elrepho 2000, Tappi T452 } \\
\text { om-83, ISO 2470, ASTM } 1925\end{array}$ & 92.3 & 92.4 & 92.3 & 92.4 & 92.5 & 92.3 \\
\hline Roughness, Parker Print Surf, $\mu \mathrm{m}, 20 \mathrm{~kg} / \mathrm{cm}$ & 16.8 & 15.2 & 14.8 & 13.7 & 13.6 & 13.6 \\
\hline $100 \mathrm{~kg} / \mathrm{cm}$ & 14.2 & 13.1 & 12.7 & 11.8 & 11.9 & 11.8 \\
\hline
\end{tabular}

Table 11. Coating, drying and calendaring conditions of coated paper.

\begin{tabular}{lcccc}
\hline \multirow{2}{*}{ Coating Condition } & \multicolumn{2}{c}{ Drying conditions } & Calendering Condition \\
& & Constant & Drying \\
Coater & Coat Weight & temperature & Laboratory softcalender \\
& & oven & Time & machine PE-204, 3 rolls \\
\hline KCC Coater & $20 \mathrm{~g} / \mathrm{cm}^{2}$ & $135^{\circ} \mathrm{C}$ & 5 minutes & $120^{\circ} \mathrm{C}, 2$ nips \\
\hline
\end{tabular}

Sheet gloss was measured using BYK Gardner Micro-Gloss 75 measured at 75 degree angle (TAPPI T480 om-92 method), and surface roughness was measured using parker Print Surf testing machine with air pressure $20 \mathrm{~kg} / \mathrm{cm}$ and $100 \mathrm{~kg} / \mathrm{cm}$ (TAPPI Method T 538).

Each samples were calendered on the laboratory calendering machine PE 7006 in the machine direction (MD) with 2 nips under heated temperature $120^{\circ} \mathrm{C}$ and pressure $64 \mathrm{~kg} / \mathrm{cm}$. Temperature and pressure were kept constant during calendering processes.

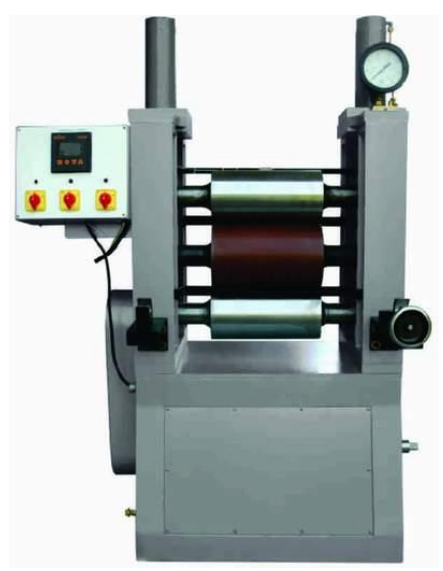

Figure 11. Laboratory calendering machine PE7006 (Premier Enterprise, India).

Table 10 shown effect of laponite organoclay in latexes to sheet gloss and roughness of coated paper, however surface brightness of coated paper has no effect on addition of laponite organoclay. There is a strong non-linear correlation between additions of organo laponite clay to micro gloss of coated paper on $4.0 \mathrm{wt} \%$ addition level, higher level of organoclay addition has less effect on sheet gloss. The reason for non-linearity of micro gloss of coated paper with addition of organo laponite clay may be due to limitation measurement of sheet gloss value on $75^{\circ}$ measurement angle, this 
limitation also reported by Mac Gregor - Johansson and Ernesto Ganer, Ramin Farnood and Ning Yan [44, 45]. Raising calendaring temperature above coalescence temperature of latex can achieve little smoothness gain, however increase in microgloss is found to be linear as reported by Ramin $\mathrm{F}$ and Ning Yan [45]. The impact of roughness on coated paper is found more dependence on pigment type than calendering temperature.

\subsubsection{Printing properties}

Illustration of printing properties by coating can be found on Figure 12.

\begin{tabular}{|c|c|}
\hline \multicolumn{2}{|c|}{ Printing Properties } \\
\hline \multicolumn{2}{|l|}{ Pigments } \\
\hline \multicolumn{2}{|l|}{ Binder } \\
\hline Co-binder & Printing gloss (Ink gloss) \\
\hline Drying & Ink Drying (Set off) \\
\hline Coat weight & Picking Strength (Dry Pick and Wet Pick) \\
\hline Coater & Mottling \\
\hline Calendering & Smoothness \\
\hline Base paper & \\
\hline
\end{tabular}

Figure 12. Factor influence on printing properties of coated paper.

Based on printing requirements, there are many main characteristics needed, high technology styrene butadiene latex were synthesized to meet these printing requirements. In the past, mixtures of latex with co-binder systems were used to achieve the requirements in order to improve paper quality with limited success. Soluble binder such as starch are used in coating formulation to replace part of the latex due to cost reasons, however lower printability is one of the main reason to limit use of starch. In fact, starch could decrease sheet gloss and increase mottling tendency through uneven migration of binder. High binding power of latex synthesized through nanocomposite technology allows decrease in binder level while maintain higher porosity and good coating cohesion (dry and wet cohesion).

Table 12. Printing properties of coated paper with difference type of latexes.

\begin{tabular}{|c|c|c|c|c|c|c|c|}
\hline Printing properties & & Latex A & Latex B & Latex C & Latex D & Latex E & Latex F \\
\hline \multirow{2}{*}{\multicolumn{2}{|c|}{$\begin{array}{c}\text { Printing gloss, IGT AIC2-5, } 45 \text { kgf } \\
\text { Parometric Ink (OD) }\end{array}$}} & 70.0 & 72.1 & 73.2 & 73.4 & 73.8 & 73.8 \\
\hline & & & & & & & \\
\hline & $2 \mathrm{sec}$ & 0.76 & 0.88 & 0.92 & 0.93 & 0.93 & 0.94 \\
\hline & $5 \mathrm{sec}$ & 0.89 & 1.02 & 1.23 & 1.24 & 1.30 & 1.32 \\
\hline & $15 \mathrm{sec}$ & 1.11 & 1.32 & 1.52 & 1.60 & 1.62 & 1.64 \\
\hline & $30 \mathrm{sec}$ & 1.50 & 1.68 & 1.78 & 1.80 & 1.90 & 1.98 \\
\hline & Total & 4.26 & 4.90 & 5.45 & 5.57 & 5.75 & 5.88 \\
\hline K \& N Value & & 8.0 & 9.2 & 9.4 & 9.5 & 9.6 & 9.6 \\
\hline \multicolumn{8}{|l|}{ Ser off Test (OD) } \\
\hline & $30 \mathrm{sec}$ & 2.25 & 1.88 & 1.76 & 1.72 & 1.69 & 1.65 \\
\hline & $45 \mathrm{sec}$ & 1.20 & 1.00 & 0.92 & 0.90 & 0.89 & 0.82 \\
\hline & $60 \mathrm{sec}$ & 0.80 & 0.67 & 0.57 & 0.50 & 0.48 & 0.45 \\
\hline & Total & 4.25 & 3.55 & 3.25 & 3.12 & 3.06 & 2.92 \\
\hline Mottling Test & & $* * *$ & * & * & * & * & * \\
\hline
\end{tabular}




\begin{tabular}{lcccccc} 
Dry Pick Resistance, IGT AIC2-5, & 36 & 76 & 80 & 96 & 98 & 98 \\
Wet Pick Resistance, IGT AIC2-5, & 1.86 & 2.60 & 2.89 & 3.01 & 3.10 & 3.12 \\
Offset Picking, IGT IC2-5, pf=640 & 6 & $>7$ & $>7$ & $>7$ & $>7$ & $>7$ \\
\hline
\end{tabular}

Coated paper with organoclay latexes offered higher picking resistance compare to without addition of organoclay (Latex A). Higher amount of organoclay offered a better printing properties, however addition of organoclay in latex have a limitation to $4.0-6.0 \mathrm{wt} \%$. Based on emulsion polymerization results, latex with higher than $8.0 \mathrm{wt} \%$ laponite organoclay created latex instability. Based on picking resistance tests, there is a possibility to reduce latex level by $50 \%$ to $60 \%$ in coating formulation while maintaining micro porosity (porometric ink) and macro porosity (K\&N Test) of coated paper. Gloss development is linked to picking strength, reducing latex level may decrease mottling tendency without creating offset picking. Many other advantages also can be achieved such as higher sheet gloss and glueability. Reducing latex level in coatings may decreased ink gloss, however to deal with this issue the balance of porosity and ink holdout (set off) should be considered carefully.

\section{Conclusions}

Synthesisis of styrene butadiene hybrid latex with organo laponite as filler through emulsion polymerization have been done with organo laponite level from $2.0 \%$ to $10.0 \mathrm{wt} \%$. Prior to emulsion polymerization process, laponite nanoclay was modified with methyl triphenylphosphonium bromide (MTPB) with ion exchange technique. Modification of laponite nanoclay renders to change laponite nanoclay hydrophilic to organophilic. Characterization of laponite nanoclay and laponite organoclay with XRD and FTIR shown MTPB surfactant changed the morphological structure of laponite nanoclay. Synthesis of styrene butadiene hybrid latex with laponite organoclay from 2.0 to $6.0 \mathrm{wt} \%$ resulted a stable latex and higher addition of laponite organoclay ( $>8.0 \mathrm{wt} \%$ ) resulted latex instability during and after emulsion polymerization. Polymer hybrid styrene butadiene latex was applied in paper coating and resulted better optical and printing properties. Higher picking resistance of hybrid latex may use for binder reduction and resulted a cost saving.

Author Contributions: Conceptualization, Methodology, Validation and Writing Draft Preparation by BS; Data Resources, Validation by JC, Project Administration by ZZW; Writing, Review, Editing and Data Analysis by M.Pk.

Funding: This research funded by Guangdong Tianyin Industrial Company Limited, China

Acknowledgments: This work was supported by the Paper Coating Laboratory Guangdong Tianyin Industrial Co.Ltd and East China University Science and Technology (ECUST) School of Material Science and Engineering. The authors declare no competing financial interest.

Conflicts of Interest: The authors declare no conflict of interest.

\section{References}

1. Styrene Butadiene Latex. available online: https://www.mcpolymers.com/library/styrene-butadiene-latex (accessed on 16 September 2019).

2. Bacquet, G.; Isoard, J.-C. Synthetic latex binders for paper manufacture. In Surface Application of Paper Chemicals, 1st Ed.; Brander, J., Thorn, I., Eds.; Springer: Dordrecht, 1997; pp. 48-68, doi:10.1007/978-94-009-1457-5_4.

3. Kim, W.-S.; Jang, S. H.; Kang, Y. G.; Han, M. H.; Hyun, K.; Kim, W. Morphology and dynamic mechanical properties of styrene-butadiene rubber/silica/organoclay nanocomposites manufactured by a latex method. Journal of Applied Polymer Science 2012, 128, 2344-2349, doi:10.1002/app.38253.

4. Yeh, J.-M.; Chang, K.-C. Polymer/layered silicate nanocomposite anticorrosive coatings. Journal of Industrial and Engineering Chemistry 2008, 14, 275-291, doi:10.1016/j.jiec.2008.01.011. 
5. Zaarei, D.; Sarabi, A. A.; Sharif, F.; Kassiriha, S. M. Structure, properties and corrosion resistivity of polymeric nanocomposite coatings based on layered silicates. Journal of Coatings Technology and Research 2008, 5, 241-249, doi:10.1007/s11998-007-9065-5.

6. Al-Shahrani, A.; Taie, I.; Fihri, A.; Alabedi, G. Current Topics in the Utilization of Clay in Industrial and Medical Applications, 1st ed.; IntechOpen: London, UK, 2018; pp. 61-79, doi:10.5772/intechopen.74154.

7. Le Pluart, L.; Duchet, J.; Sautereau, H.; Gérard, J. F. Surface modifications of montmorillonite for tailored interfaces in nanocomposites. The Journal of Adhesion 2002, 78, 645-662, doi:10.1080/00218460213738.

8. Pazos, M. C.; Castro, M. A.; Orta, M. M.; Pavón, E.; Rios, J. S. V.; Alba, M. D. Synthetic High-Charge Organomica: Effect of the Layer Charge and Alkyl Chain Length on the Structure of the Adsorbed Surfactants. Langmuir 2012, 28, 7325-7332, doi:10.1021/la300153e.

9. Khayankarn, O.; Magaraphan, R.; Schwank, J. W. Adhesion and permeability of polyimide-clay nanocomposite films for protective coatings. Journal of Applied Polymer Science 2003, 89, 2875-2881, doi:10.1002/app.12326.

10. Yu, Y.-H.; Yeh, J.-M.; Liou, S.-J.; Chen, C.-L.; Liaw, D.-J.; Lu, H.-Y. Preparation and properties of polyimide-clay nanocomposite materials for anticorrosion application. Journal of Applied Polymer Science 2004, 92, 3573-3582, doi:10.1002/app.20400.

11. Chen, C.; Khobaib, M.; Curliss, D. Epoxy layered-silicate nanocomposites. Progress in Organic Coatings 2003, 47, 376-383, doi:10.1016/s0300-9440(03)00130-9.

12. Chern, C. S. Emulsion polymerization mechanisms and kinetics. Progress in Polymer Science 2006, 31, 443-486, doi:10.1016/j.progpolymsci.2006.02.001.

13. Neto, W.; Jensen, A.; Ferreira, G.; Valadares, L.; Gambetta, R.; Gonçalves, S.; Machado, F. A Survey on Synthesis Processes of Structured Materials for Biomedical Applications: Iron-based Magnetic Nanoparticles, Polymeric Materials and Polymerization Processes. Current Pharmaceutical Design 2015, 21, 5336-5358, doi:10.2174/1381612821666150917093031.

14. Odian, G. Principles of Polymerization, 4th ed.; John Wiley \& Sons: New Jersey, USA, 2004; pp. 350-371, doi:10.1002/047147875x.ch4.

15. Schild, H. G. Poly(N-isopropylacrylamide): experiment, theory and application. Progress in Polymer Science 1992, 17, 163-249, doi:10.1016/0079-6700(92)90023-r.

16. Lee, H. C.; Poehlein, G. W. Continuous tube-CSTR reactor system for emulsion polymerization kinetic studies. Chemical Engineering Science 1986, 41, 1023-1030, doi:10.1016/0009-2509(86)87188-3.

17. Landfester, K. Polyreactions in miniemulsions. Macromolecular Rapid Communications 2001, 22, 896-936.

18. López-Quintela, M. A.; Tojo, C.; Blanco, M. C.; García Rio, L.; Leis, J. R. Microemulsion dynamics and reactions in microemulsions. Current Opinion in Colloid $\mathcal{E}$ Interface Science 2004, 9, 264-278, doi:10.1016/j.cocis.2004.05.029.

19. López-Quintela, M. A. Synthesis of nanomaterials in microemulsions: formation mechanisms and growth control. Current Opinion in Colloid $\mathcal{E}$ Interface Science 2003, 8, 137-144, doi:10.1016/s1359-0294(03)00019-0.

20. Harkins, W. D. A General Theory of the Mechanism of Emulsion Polymerization1. Journal of the American Chemical Society 1947, 69, 1428-1444, doi:10.1021/ja01198a053.

21. Smith, W. V.; Ewart, R. H. Kinetics of Emulsion Polymerization. The Journal of Chemical Physics 1948, 16, 592-599, doi:10.1063/1.1746951.

22. El-hoshoudy, A. N. M. B. Recent Research in Polymerization, 1st ed.; IntechOpen: London, UK 2018; doi:10.5772/intechopen.72143.

23. Liu, B. J.; Deng, Y. J.; Sun, S. L.; Zhang, M. Y.; Lin, R. Q.; Zhang, H. X. A novel approach to prepare large-scale and narrow-dispersed latex particles by emulsion polymerization based on particle coagulation mechanism. Designed Monomers and Polymers 2015, 19, 119-127, doi:10.1080/15685551.2015.1124319.

24. Tong, Z.; Deng, Y. Synthesis of polystyrene encapsulated nanosaponite composite latex via miniemulsion polymerization. Polymer 2007, 48, 4337-4343, doi:10.1016/j.polymer.2007.05.032.

25. Negrete-Herrera, N.; Putaux, J.-L.; Bourgeat-Lami, E. Synthesis of polymer/Laponite nanocomposite latex particles via emulsion polymerization using silylated and cation-exchanged Laponite clay platelets. Progress in Solid State Chemistry 2006, 34, 121-137, doi:10.1016/j.progsolidstchem.2005.11.040. 
26. He, H.; Frost, R. L.; Bostrom, T.; Yuan, P.; Duong, L.; Yang, D.; Xi, Y.; Kloprogge, J. T. Changes in the morphology of organoclays with HDTMA+ surfactant loading. Applied Clay Science 2006, 31, 262-271, doi:10.1016/j.clay.2005.10.011.

27. Xi, Y., Frost, R. L., \& He, H. Modification of the surfaces of Wyoming montmorillonite by the cationic surfactants alkyl trimethyl, dialkyl dimethyl, and trialkyl methyl ammonium bromides. Journal of Colloid and Interface Science 2007, 305, 150-158, doi:10.1016/j.jcis.2006.09.033.

28. Bergaya, F.; Lagaly, G. Handbook of Clay Science, 2nd ed.; Elsevier: Amsterdam, Netherland, 2013; pp. $1-1752$.

29. Source clays data. Available online: http://www.clays.org/sourceclays_data.html (accessed on 16 September 2019).

30. Giguère, P. A.; Harvey, K. B. On the infrared absorption of water and heavy water in condensed states. Canadian Journal of Chemistry 1956, 34, 798-808, doi:10.1139/v56-103.

31. Laurens,D.; Kim, R.; Joris,D,;Ludwiq, C. The effect of multiple extrusions on the properties of montmorillonite filled polypropylene. Polymers, 2014, 6 (12), 2912-2927, https://doi.org/103390/polym6122912.

32. Zhang, K,; Borg, JP,; Fei, F.F,; Hyoung, J.C. Sonochemical preparation of polymer nanocomposites. Molecules, 2009, 14, 2095-2110. Doi 10.3390/molecules14062095, ISSN: 1420-3049

33. Katarzyna, B,; Louis, R,; Jerzy, D,; Wilma,D,; Anke, B,; Dariusz, B. Influence of network structure on glass-transition temperature of elastomers. Materials, 2016, 9 607, doi: 10. 3390/ma9070607.

34. Lu, ZC,; Kong, XM,; Zhang, CY, Zhang, YR. Effect of polymer latexes with varied glass-transition temperature on cement hydration. Journal of Applied Science, 134(36), 2017, 45264. Doi: 10.1002/app45264.

35. Bartolomeo, C,; Nicola, C,; Luciano, DM,; Paola, S,; Loredana, I. 3D printing of PLA/clay nanocomposites:Influence of printing temperature on printed sample properties. Materials, 2018 11(10) 1947, https://doi.org/10.3390/ma11101947

36. Joanicot, M.; Wong, K.; Richard, J.; Maquet, J.; Cabane, B. Ripening of cellular latex films. Macromolecules 1993, 26, 3168-3175, doi:10.1021/ma00064a029.

37. Rajabi Abhari, A.; Lee, H. L.; Oh, K.; Im, W.; Lee, J.-H.; Lee, S.; Kim, S. Suspension-polymerized Latex as an Additive for Surface Sizing and Its Effect on Fold Cracking of Coated Paper. BioResources 2018, 13, doi:10.15376/biores.13.4.7640-7653.

38. Salminen, P. Studies of water transport in paper during short contact times. Doctor Thesis, Ph.D- Åbo Akademi University, Finland, 1988.

39. Dickson, R.; Forsström, U. Coating coverage of metered size press pre-coated paper. Nordic Pulp $\mathcal{E}$ Paper Research Journal 2002, 17, 434-439, doi:10.3183/npprj-2002-17-04-p434-439.

40. Kimpimäki, T.; Savolainen, A. V. Surface Application of Paper Chemicals, 1st ed.; Springer: Dordrecht, 1997; pp. 208-228.

41. Richmond, F. Cellulose Nanofibers Use in Coated Paper. Doctor Thesis, Ph.D- University of Maine, USA, 2014.

42. Linnonmaa, J., Trefz, M.,"Chapter 14: Coating and surface sizing technologies", (2009), Pigment coating and surface sizing of paper, pp. 462-546, Gummerus, Oy, ISBN 978-952-5216-27-1.

43. Emilia Golebiowska, "Starch and latex migration in paper coating. A study of effect of different process and coating parameter on binder migration", (2015), M.S. Thesis, University of Maine.

44. Mac Gregor, M.A., Johansson, P.A." Gloss in uniformity in coated paper. Measurements of commercial papers". (1991). Coat. Conf. Proceedings, Tappi, Press, Atlanta, GA, p. 495-504.

45. Ernesto Ganer, Ramin Farnood, Ning Yan," Effect of the Coating Formulation on the Gloss Properties of Coated Papers," (2015). University of Toronto, Ontario, Canada. 